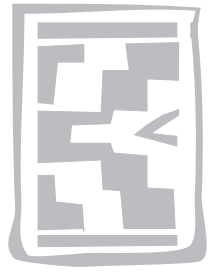

\title{
Study on the efficacy and safety of different antigens and oil formulations of infectious coryza vaccines containing an NAD-independent strain of Avibacterium paragallinarum
}

\author{
B. DUNGU ${ }^{1 *}$, B. BRETT ${ }^{1}$, R. MACDONALD ${ }^{1}$, S. DEVILLE ${ }^{2}$, L. DUPUIS ${ }^{2}$, J. THERON $^{3}$ and \\ R.R. BRAGG ${ }^{4}$
}

\begin{abstract}
DUNGU, B., BRETT, B., MACDONALD, R., DEVILLE, S., DUPUIS, L., THERON, J. \& BRAGG, R.R. 2009. Study on the efficacy and safety of different oil formulations of infectious coryza vaccines containing a NAD-independent strain of Avibacterium paragallinarum. Onderstepoort Journal of Veterinary Research, 76:299-309

The present study was designed to assess and compare three different formulations of the new Onderstepoort infectious coryza (IC) quadrivalent vaccine, which contain an NAD-independent strain of Avibacterium paragallinarum (previously known as Haemophilus paragallinarum), and a commercial IC vaccine, not containing an NAD-independent strain, for their safety and ability to protect chickens of varying ages against virulent challenges with four different serovars of A. paragallinarum, including the NAD-independent strain of the C-3 serovar.

Four groups of 140 chickens each were vaccinated at the age of 17 weeks and revaccinated at the age of 19 weeks with each of the four vaccine formulations. A similar sized group of non-vaccinated chickens was used as control. Two rounds of challenge were conducted: a group of chicken in each vaccination group was challenged between 31 and 35 weeks of age, while another group was challenged between 51 and 55 weeks of age. The "in-contact" challenge model was used in this experiment. For each vaccination group, the four challenge strains representing four local serovars were used in each challenge round. The efficacy of the vaccines was compared based on overall protection levels obtained and the duration of protection. The safety of the different vaccines was determined by the severity of post-vaccination reactions.

The need for the incorporation of the NAD-independent strain in the vaccine was evidenced by the low protection level against NAD-independent challenge recorded in the group of birds vaccinated with the commercial vaccine. The results obtained confirmed not only the variation in virulence of different South African serovars, with serovar C-3 being the most virulent and serovar B having almost no virulence but also the age related increase in susceptibility. The importance of a suitable formulation of the vaccine is discussed.
\end{abstract}

Keywords: Avibacterium paragallinarum, C-3 serovar, chickens, coryza vaccine, NAD-independent strain

* Author to whom correspondence is to be directed. Present address: GALVmed, Edinburgh EH26 OPZ Scotland, UK. E-mail: Baptiste.Dungu@galvmed.org

1 Onderstepoort Biological Products, Private Bag X07, Onderstepoort, 0110 South Africa

2 SEPPIC, Tour Kupka C-7, Bld Franck Kupka, 92039 Paris, France

3 Department of Microbiology and Plant Pathology, University of Pretoria, Pretoria, 0002 South Africa

4 University of the Free State, P.O. Box 339, Bloemfontein, 9300 South Africa

Accepted for publication 19 April 2009-Editor

\section{INTRODUCTION}

Infectious coryza (IC) is an acute respiratory disease of chickens and the cause of serious economic losses as a result of an increased number of culls and a drop in egg production in laying flocks. The impact on broilers has been also shown during outbreaks in the USA (Droual, Bickford, Charlton, Cooper \& Channing 1990). The causative agent $A$. paragallinarum, (Blackall, Christensen, Beckenham, Blackall \& Bisgaard 2005) is a bacterial organism 
that can be either NAD (or V-factor) dependent or independent (Mouahid, Bisgaard, Morley, Mutters \& Mannheim 1992; Bragg, Coetzee \& Verschoor 1993) for growth in vitro. Three serogroups are recognised, namely A, B and C (Page 1962), with up to four serovars within serogroup $A$ and $C$ (Kume, Sawata, Nakai \& Matsumoto 1983; Blackall, Eaves \& Rogers 1990).

The role played by NAD-independent serovars has been extensively studied in South Africa (Miflin, Horner, Blackall, Chen, Bishop, Morrow, Yamaguchi \& Iritani 1995; Bragg, Coetzee \& Verschoor 1996), where they have been shown to be the most dominant serovars in certain provinces such as KwaZulu-Natal.

Since first recorded in South Africa in the late 1960s (Buys 1982), IC has occurred widely in different parts of the country. Despite the introduction of a vaccine in the mid-1970s, which seemed to decrease the incidence of the disease, more outbreaks were recorded in the 1980s. Studies conducted by Bragg et al. (1996) demonstrated a significant shift in the incidence of the four serovars occurring in the country over a 30-year period. Serovar C-3 had become predominant, representing $73 \%$ of isolated serovars in the 1990s, mainly in the period following the introduction of the vaccine, which did not include C-3. This work and the work by other researchers demonstrated and confirmed the importance of including locally occurring serovars in the vaccine for effective control (Terzolo, Sandoval \& Gonzalez Pondal 1997; Blackall 1999).

Inactivated multivalent vaccines are used worldwide for the control of IC, most of them comprising serovars of serogroups A, B and C (Blackall1999). As for most inactivated vaccines, the adjuvant used for the formulation of the vaccine plays a critical role in defining the type of protection afforded by the antigen and the duration of immunity. Most IC vaccines are formulated with an oil emulsion. Ideally the vaccine should provide effective protection while being safe and having the least effect on chicken productivity. A long-lasting immunity is therefore preferred in order to avoid re-vaccinating layers during their production period. Water-in-oil emulsions are thus commonly used as they are known to induce strong and long-term immunity (Aucouturier, Dupuis \& Ganne 2001). One of their main disadvantages, however, is the possibility of local reactions when used with a crude antigen (Dupuis, Ascarateil, Aucouturier \& Ganne 2006). Double oil emulsions, consisting of a water-in-oil-in-water emulsion are usually safer and also suitable for poultry (Dupuis et al. 2006).
Depending on the type of formulations, type of emulsifying agent, the surfactant used and many other factors, different responses can be obtained with different formulation that will affect the protection ability of the vaccine, hence the need for in vivo evaluations.

An effective combination of a relevant vaccine strain and suitable adjuvant are critical for ensuring that the vaccine provides optimal protection.

Since its introduction in the mid-1970s the Onderstepoort Biological Products (OBP) IC vaccine has been adjusted to include the main serovars occurring in the country. The latest vaccine, CoryzaPlus vaccine, includes a C-3 NAD-independent strain together with locally occurring serovar $A$ and $C$ isolates.

The present study was designed to evaluate the efficacy and safety of alternative experimental oil vaccines formulated with the same vaccine antigens as the OBP CoryzaPlus IC vaccine but using different oil adjuvants. The safety and ability of these formulations to provide long term protection to layers kept throughout a production cycle were compared to those of an international IC commercial vaccine registered in South Africa.

\section{MATERIAL AND METHODS}

\section{Vaccines}

The OBP CoryzaPlus vaccine was used in the study, together with two experimental oil vaccines formulated with the same vaccine antigens as the OBP vaccine and a commercial vaccine, referred to as "ComA". The OBP CoryzaPlus vaccine is a waterin-oil emulsion of formalin-inactivated $A$. paragallinarum strains. It is a quadrivalent vaccine containing serotypes A and C (2 strains) and a C-3 NADindependent vaccine strain. The same strains were used to formulate two experimental vaccines: one with the water-in-oil-in-water double emulsion Montanide ${ }^{\mathrm{TM}}$ ISA $206 \mathrm{VG}$ (Seppic) and the other with the water-in-oil emulsion, Montanide ${ }^{\mathrm{TM}}$ ISA 70 VG (Seppic). The commercial vaccine is a water-in-oil emulsion containing serovar $\mathrm{A}, \mathrm{B}$ and $\mathrm{C}$, but not the NAD-independent strain.

The emulsions of the experimental vaccines were evaluated at the SEPPIC vaccine department laboratory in Castres (France) for physical and chemical properties using the KF values, the aspect, the particle size and the stability at $4{ }^{\circ} \mathrm{C}$, room temperature 
and $37^{\circ} \mathrm{C}$ up to 1 month. They were compared to a placebo emulsions made of a saline solution.

\section{Chickens}

In order to ensure homogeneity among the chickens to be studied, 750 fertilized eggs were procured and incubated simultaneously at the Agriculture Research Council (ARC) Poultry Research Centre at Glen Agriculture College, situated near Bloemfontein in the Free State Province, South Africa. Hatched chicks were kept for 16 weeks before being placed randomly into groups of 70 birds each. Two of the groups, totalling 140 chicks, were used for each vaccine, and the same number for non-vaccinated controls.

For the challenge experiment, specific groups of birds were transferred to isolated layer facilities in the Animal House of the University of the Free State, Bloemfontein (UFS). This experiment was performed with the approval of the UFS Ethics Committee under project number 04/04.

\section{Bacterial isolates used for challenge}

The challenge strains used in this experiment represented all three recognised serogroups of $A$. paragallinarum and major strains known to occur in South Africa. Serovar C-3 (Tongaat) strain of $A$. paragallinarum, known to be highly virulent and very prevalent in South Africa was used, in parallel with Strain C-2 (serovar C-2), isolate 0083 (serogroup A), Strain B (serogroup B) and the NAD-independent strain 1750 (serovar C-3).

The purity of each of the challenge strains was established by plating out the challenge bacteria onto BTA plates, streaking with Staphylococcus aureus and incubating at $37^{\circ} \mathrm{C}$.

\section{Vaccination and challenge experiments}

Chickens in the four study groups were vaccinated at 17 weeks of age, and boosted 3 weeks later. The birds were vaccinated by the subcutaneous injection of $0.5 \mathrm{ml}$ of the respective vaccines during both vaccination procedures. All vaccinations were conducted by the same operator. The safety of each vaccine was assessed by evaluating local reactions in vaccinated chickens during the first week postinoculation. This evaluation was conducted on a number of chickens randomly selected in each group, during the first and the second vaccination. Post vaccination signs recorded were principally swellings of different sizes. They were graded as "none", when there was no detectable swelling, "mild" for a small lesion and "severe" when there was a prominent swelling, sometimes affecting the general health of the chicken.

Two rounds of challenges were conducted. The first round of challenges with virulent strains of $A$. paragallinarum was conducted when the birds were between 31 and 35 weeks of age (from 15 weeks post vaccination).

The second round of challenge, conducted in the remaining unchallenged vaccinated chickens, took place when they were between 51 and 55 weeks of age. As controls, unvaccinated chickens of similar age were included in all challenge experiments.

The challenge method used was according to the "in-contact" challenge model established by Bragg (2002a), in which one bird in a group of ten birds is directly challenged by intra-sinus injection with $0.1 \mathrm{~m} \ell$ of a bacterial suspension. The remaining birds in the group are challenged through natural in-contact route as the ten birds in each group are in adjoining cages with a communal water supply. The clinical signs were recorded and scored over the 20 days post-challenge observation period, according to the method described by Bragg (2002a), and used to calculate percentage protection according to the above method.

Due to space constraints at the animal laboratory facility of the UFS, each round of vaccination was divided into two phases. For the first round of challenge (at Week 31 of age), the first phase involved the Tongaat strain, the C-2 strain and the 0083 strain. The cage were then cleaned, disinfected and left empty for a week before conducting the second phase with the NAD-independent strain and the serogroup $B$ strain. For the second round, the first phase (Week 51 of age) involved the Tongaat and the C-2 strains, while the second phase involved strain 0083 and the NAD-independent strain 1750.

\section{RESULTS}

\section{Stability of the experimental IC oil vaccines}

Tables $1 \mathrm{~A}$ and $1 \mathrm{~B}$ summarize the results obtained for the physical characteristic evaluation and stability of the two experimental vaccines formulated with Montanide ${ }^{\mathrm{TM}}$ ISA $206 \mathrm{VG}$ and Montanide ${ }^{\mathrm{TM}}$ ISA 70 $V G$ respectively. Each one of the two experimental coryza vaccines had comparable physical characteristics to the equivalent SEPPIC placebo in terms 
Infectious coryza vaccines containing an NAD-independent strain of Avibacterium paragallinarum

TABLE 1A Comparative evaluation of the Coryza special vaccine formulated with ISA 206 adjuvant, and a SEPPIC placebo emulsified in the same adjuvant. Karl Fisher method (KF) defines the emulsion water content while $D(v)$ is the mean of particles diameter

\begin{tabular}{|l|l|l|l|l|l|}
\cline { 2 - 5 } \multicolumn{1}{c|}{} & $\begin{array}{l}\text { Type of } \\
\text { emulsion }\end{array}$ & $\begin{array}{l}\text { KF } \\
(\%)\end{array}$ & $\begin{array}{l}\mathbf{D}(\mathbf{v}, \mathbf{0 . 5}) \\
\mathbf{D}(\mathbf{v}, \mathbf{0 . 9}) \text { in } \mu \mathrm{m}\end{array}$ & $\begin{array}{l}\text { Stability after 15 } \\
\text { days } \\
\mathbf{4}^{\circ} \mathbf{C} / \mathbf{R T} / 37^{\circ} \mathbf{C}\end{array}$ & $\begin{array}{l}\text { Stability after one } \\
\text { month } \\
\mathbf{4}^{\circ} \mathbf{C} / \mathbf{R T} / 37^{\circ} \mathbf{C}\end{array}$ \\
\hline $\begin{array}{l}\text { SEPPIC placebo } \\
\text { emulsion }\end{array}$ & W/O/W & 47.5 & $\begin{array}{l}0.26 \\
0.62\end{array}$ & OK/OK/Deph & OK/OK/Deph \\
\hline $\begin{array}{l}\text { Coryza ISA 206 } \\
\text { vaccine }\end{array}$ & W/O/W & 49.0 & 0.24 & OK/OK/BR & OK/OK/BR \\
& & & 0.42 & & \\
\hline
\end{tabular}

TABLE 1B Comparative evaluation of the coryza special vaccine formulated with ISA 70 adjuvant and a SEPPIC placebo emulsified in the same adjuvant. Karl Fisher method (KF) defines the emulsion water content while D (v) is the mean of particles diameter

\begin{tabular}{|c|c|c|c|c|c|}
\hline & $\begin{array}{l}\text { Type of } \\
\text { emulsion }\end{array}$ & $\begin{array}{l}\text { KF } \\
(\%)\end{array}$ & $\begin{array}{l}D(v, 0.5) \\
D(v, 0.9) \\
\text { in } \mu \mathrm{m}\end{array}$ & $\begin{array}{l}\text { Stability after } 15 \\
\text { days } \\
4{ }^{\circ} \mathrm{C} / \mathrm{RT} / 37^{\circ} \mathrm{C}\end{array}$ & $\begin{array}{l}\text { Stability } 1 \text { month } \\
4^{\circ} \mathrm{C} / \mathrm{RT} / 37^{\circ} \mathrm{C}\end{array}$ \\
\hline $\begin{array}{l}\text { SEPPIC placebo } \\
\text { emulsion }\end{array}$ & W/O & 29.0 & $\begin{array}{l}0.33 \\
0.84\end{array}$ & OK/OK/OK & $\mathrm{OK} / \mathrm{OK} / \mathrm{OK}$ \\
\hline $\begin{array}{l}\text { Coryza ISA } 70 \\
\text { vaccine }\end{array}$ & W/O & 29.8 & $\begin{array}{l}0.26 \\
0.55\end{array}$ & OK/OK/OK & OK/OK/OK \\
\hline
\end{tabular}

of homogeneity and particle size. They all were also stable for a month at $4^{\circ} \mathrm{C}$ and room temperature.

\section{Post-vaccinal safety of the vaccines}

Vaccination reactions were recorded during the first week post-vaccination in all groups, following the first and second vaccination. The results of the vaccination reaction observations are given in Table 2 and Fig. 1 and 2.

After the first vaccination, no vaccination reactions were seen in the control group (which were not vaccinated) and in the birds vaccinated with the Montanide ${ }^{\text {TM }}$ ISA 206 VG vaccine. The most severe clinical signs were observed in the birds vaccinated with the OBP IC vaccine and the Montanide ${ }^{\mathrm{TM}}$ ISA 70 VG formulation.

After the second vaccination, no reactions were observed in the control group or in the birds vaccinated with the Montanide ${ }^{\mathrm{TM}}$ ISA 206 VG formulation. The worst vaccination reactions were seen in the group of birds vaccinated with the ComA vaccine, with $20 \%$ of the birds showing very severe vaccination reactions characterized by subcutaneous swelling of varying degree. In some cases, the vaccination reactions were so severe that these birds were removed from the experiment for ethical reasons as their general health condition was seriously deteriorating. 
B. DUNGU et al.

TABLE 2 The number of birds showing vaccination reactions for each of the different vaccines

\begin{tabular}{|c|c|c|c|c|c|c|c|c|}
\hline \multirow{2}{*}{ Vaccine } & \multicolumn{4}{|c|}{$1^{\text {st }}$ vaccination } & \multicolumn{4}{|c|}{$2^{\text {nd }}$ vaccination } \\
\hline & No. birds & No & Mild & Severe & No. birds & No & Mild & Severe \\
\hline Control & 60 & $60(100 \%)$ & 0 & 0 & 60 & $60(100 \%)$ & 0 & 0 \\
\hline ComA & 50 & 36 (72 \%) & $12(24 \%)$ & $2(4 \%)$ & 83 & 43 (52 \%) & 23 (28 \%) & $17(20 \%)$ \\
\hline ISA 206 & 50 & 46 (92 \%) & $4(8 \%)$ & $0(0 \%)$ & 78 & $78(100 \%)$ & 0 & 0 \\
\hline OBP IC & 45 & $23(51 \%)$ & $17(38 \%)$ & $5(11 \%)$ & 122 & $103(84 \%)$ & $4(3 \%)$ & $15(12 \%)$ \\
\hline ISA 70 & 46 & 28 (61 \%) & $14(30 \%)$ & $4(9 \%)$ & 154 & 149 (97 \%) & $3(2 \%)$ & $2(1 \%)$ \\
\hline
\end{tabular}

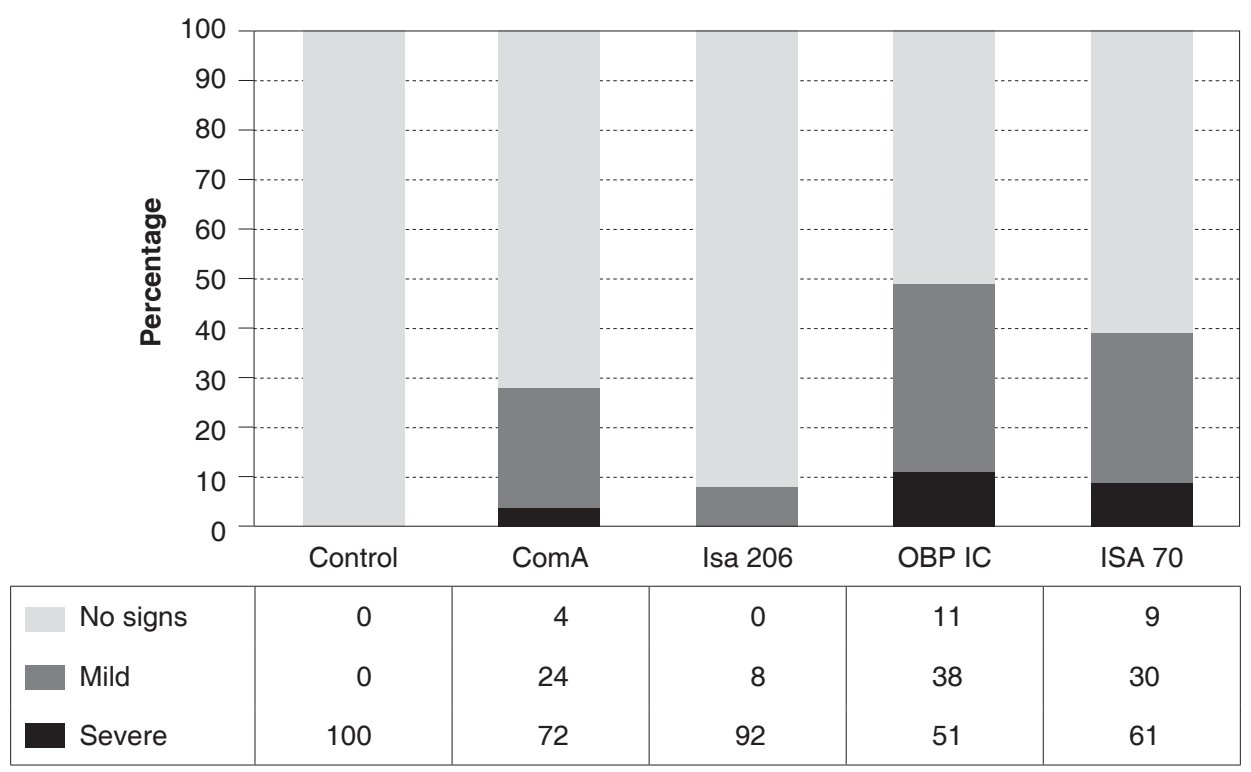

FIG. 1 Graphic representation of the percentage of vaccination reactions obtained after the first vaccination with the different vaccines used in this experiment



FIG. 2 Graphic representation of the vaccination reactions obtained after the second vaccination with the different vaccines used in this experiment 
Infectious coryza vaccines containing an NAD-independent strain of Avibacterium paragallinarum

TABLE 3A First vaccination: Graphic representation of the mean daily disease scores obtained from each of the vaccines for chickens challenged with different $A$. paragallinarum challenge strains and table summarizing the corresponding mean lesion score and percentage protection-the Tongaat (C-3) strain (1); C-2 strain (2); the A-1 isolate 0083 (3); and the NADindependent C-3 isolate 1750 (4)

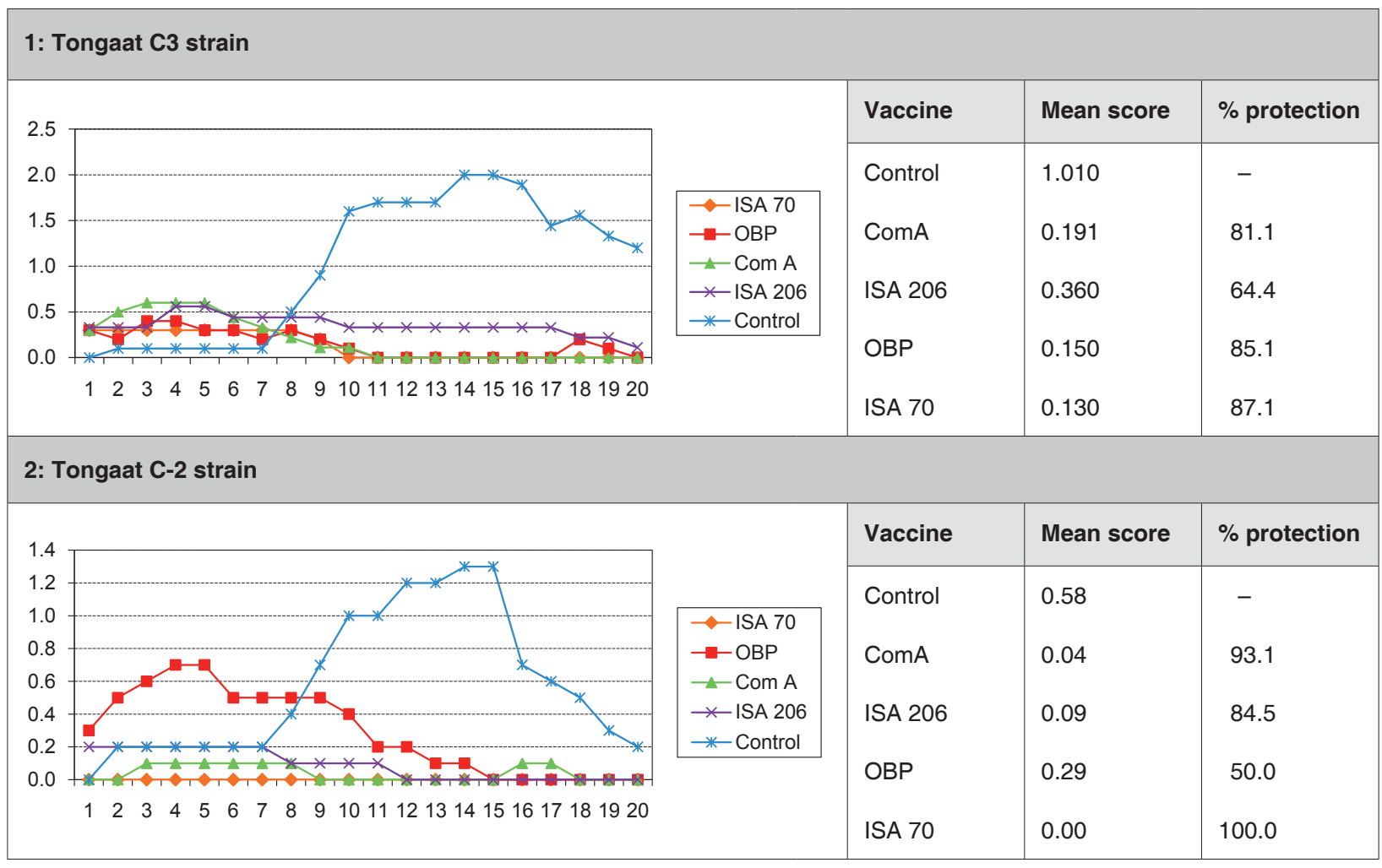

\section{3: A-1 isolate 0083}
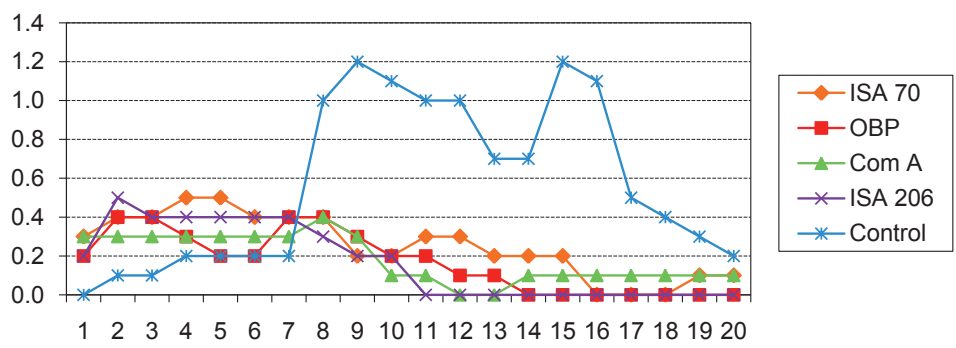

\begin{tabular}{|l|l|l|}
\hline Vaccine & Mean score & \% protection \\
\hline Control & 0.55 & - \\
ComA & 0.19 & 65.5 \\
ISA 206 & 0.17 & 69.1 \\
OBP & 0.20 & 63.6 \\
ISA 70 & 0.26 & 52.7 \\
\hline
\end{tabular}

\section{4: NAD-independent C-3 isolate 1750}

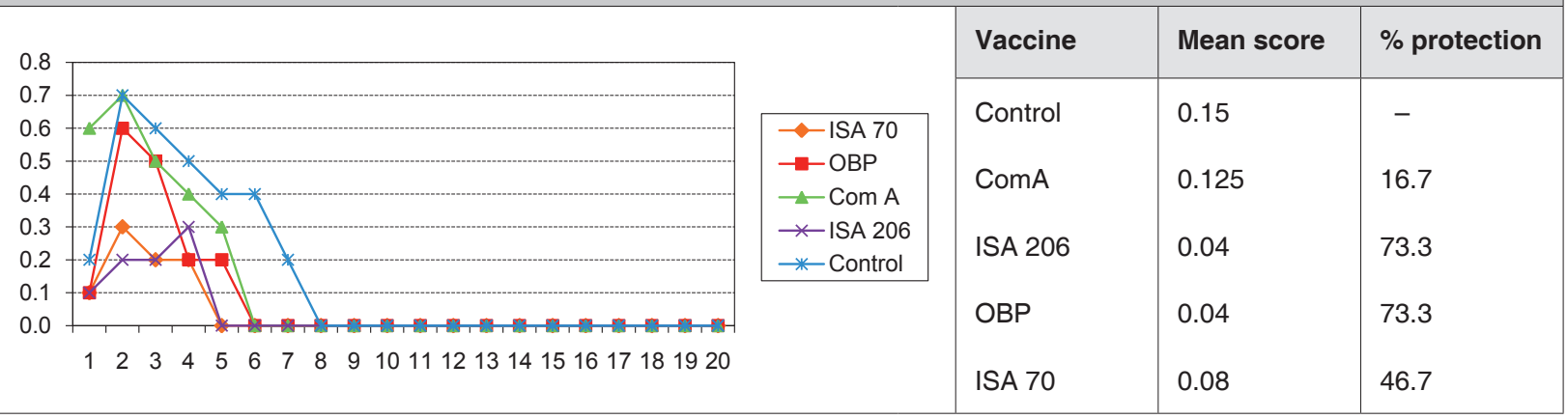


TABLE 3B Second vaccination: Graphic representation of the daily protection scores provided by each of the vaccines for chickens challenged with different $A$. paragallinarum challenge strains and table summarizing the corresponding mean lesion score and percentage protection-the Tongaat (C-3) strain (1); C-2 strain (2); the A-1 isolate 0083 (3); and the NADindependent C-3 isolate 1750 (4)

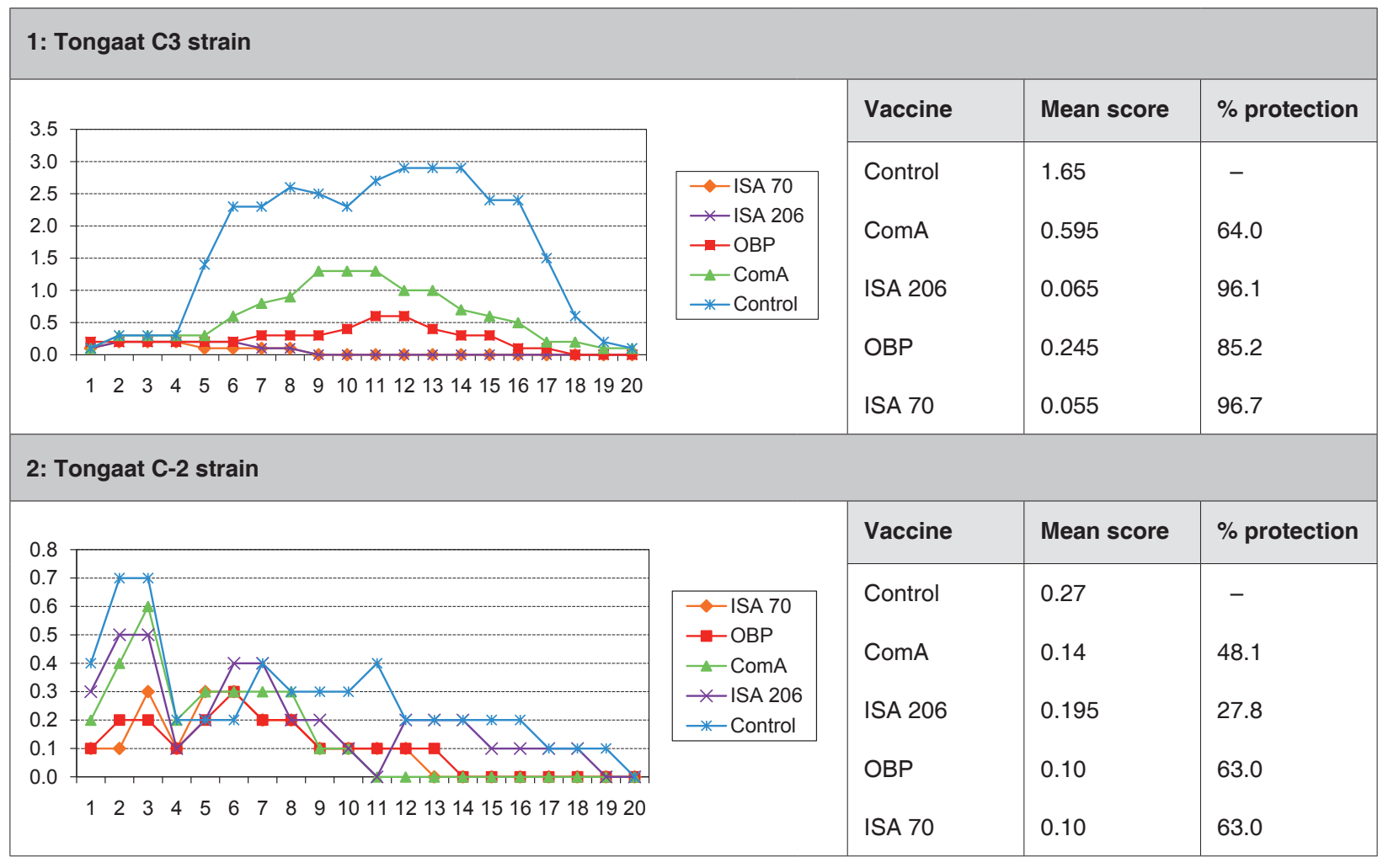

\section{3: A-1 isolate 0083}

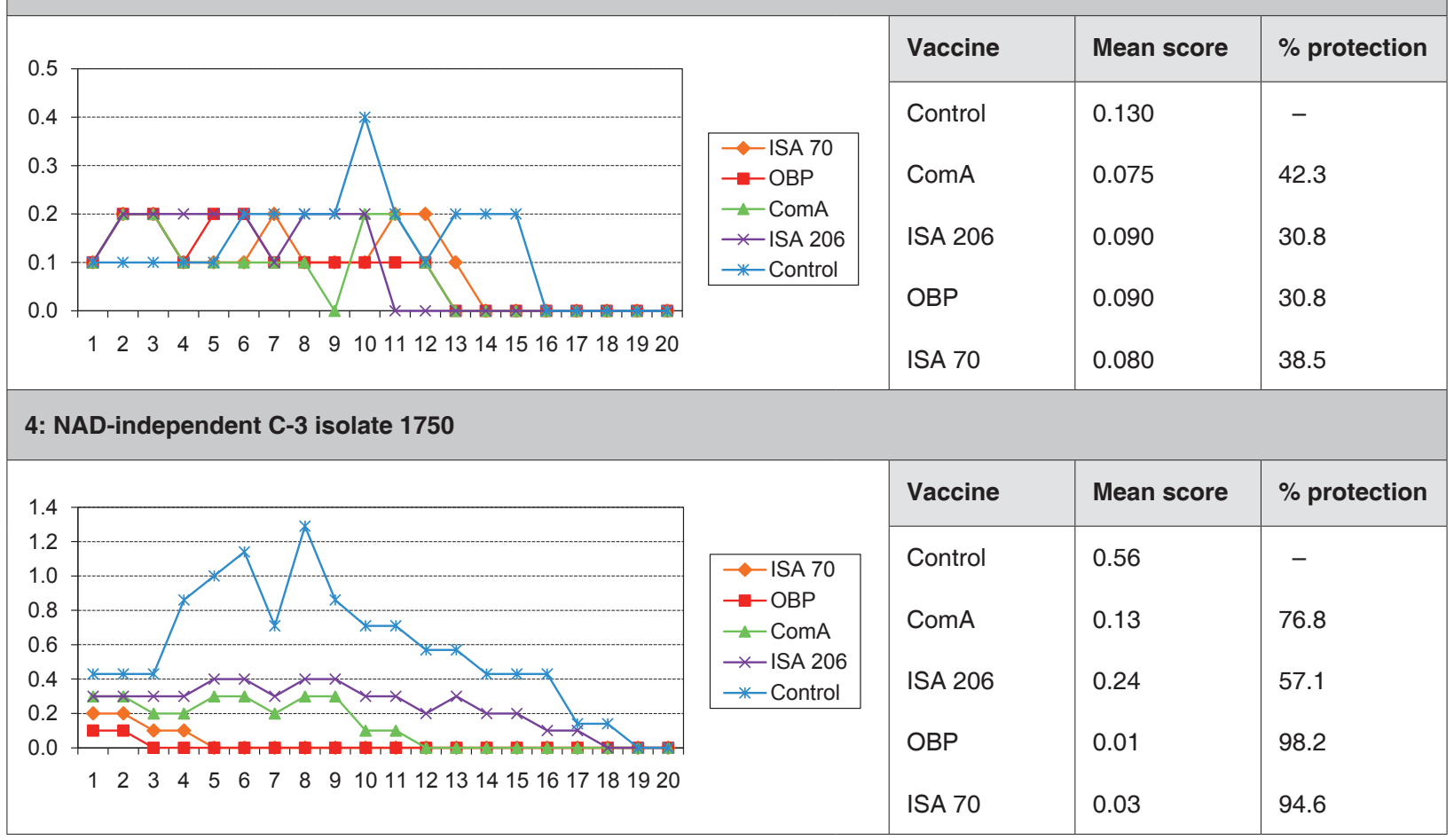


Infectious coryza vaccines containing an NAD-independent strain of Avibacterium paragallinarum

TABLE 4 Comparison of all of the vaccines based on percentage protection against the NAD-dependent, NAD-independent strain and for all of the challenge strains used (excluding serovar B-1, which did not result in any clinical signs when used to challenge chickens in this experiment, including the unvaccinated controls). Mean protections obtained for the first and second round of challenges for all of the vaccines and challenged strains used in this experiment are also included

\begin{tabular}{|c|c|c|c|c|c|c|c|c|}
\hline \multirow{2}{*}{ Challenge } & \multicolumn{2}{|c|}{ ComA } & \multicolumn{2}{|l|}{ OBP } & \multicolumn{2}{|c|}{ Isa 206} & \multicolumn{2}{|c|}{ Isa 70} \\
\hline & $1^{\text {st }}$ & $2^{\text {nd }}$ & $1^{\text {st }}$ & $2^{\text {nd }}$ & $1^{\text {st }}$ & $2^{\text {nd }}$ & $1^{\text {st }}$ & $2^{\text {nd }}$ \\
\hline C-3 & 81.1 & 64.0 & 85.1 & 85.2 & 64.4 & 96.1 & 87.1 & 96.7 \\
\hline C-2 & 93.1 & 48.1 & 50.0 & 63.0 & 84.5 & 27.8 & 100.0 & 63.0 \\
\hline$A-1$ & 65.5 & 42.3 & 63.6 & 30.8 & 69.1 & 30.8 & 54.7 & 38.5 \\
\hline Mean NAD-dependent protection & 79.9 & 51.5 & 66.2 & 59.7 & 72.7 & 51.6 & 80.6 & 66.1 \\
\hline NAD-independent C-3 & 16.7 & 76.8 & 73.3 & 98.2 & 73.3 & 57.1 & 46.7 & 94.6 \\
\hline Mean overall protection (all isolate) & 64.1 & 64.2 & 68.0 & 78.9 & 72.8 & 54.3 & 72.1 & 80.3 \\
\hline
\end{tabular}

\section{Efficacy of the vaccine formulations to different serovar after the first challenges}

The mean daily disease and protection scores for each of the groups of birds are summarized in Tables $3 \mathrm{~A}$ and $\mathrm{B}$ for the first and second challenge rounds presented below.

No clinical signs occurred in birds challenged with the strain of serovar B, thus the efficacy of the vaccine against serogroup $B$ could not be determined.

The percentage protection calculated from the disease challenge and a comparison of the mean disease scores in the first and second rounds are presented in Table 4.

\section{DISCUSSION}

Vaccine reactions of varying degrees occurred in all groups after the first vaccination, irrespective of the type of vaccine. The least severe vaccination reactions were seen in the chickens which received the Montanide ${ }^{\mathrm{TM}}$ ISA 206 VG formulation, which can be attributed to the fact that this was the only formulation in which the continuous phase is aqueous (water-in-oil-in-water), therefore causing the least inflammatory local reaction as compared to water in oil emulsions (Jansen, Hofmans, Theelen, Manders \& Schijns 2006). After the second round of vaccination, the birds vaccinated with the ComA vaccine showed the most severe vaccination reactions: a total of 14 birds were removed from the experiment for ethical reasons based on the severity of their reactions. The two experimental formulations induced vaccination reactions in only $3 \%$ of the birds with the Montanide ${ }^{\mathrm{TM}}$ ISA $70 \mathrm{VG}$ formulation and none of the birds inoculated with the Montanide ${ }^{\mathrm{TM}}$ ISA
206 VG formulation. Overall, the Montanide ${ }^{\mathrm{TM}}$ ISA formulations showed the least number of local postvaccination reactions.

A quadrivalent vaccine needs a potent adjuvant to induce protection. The reactogenic properties of the inactivated bacteria used as antigen in the present vaccines require a safe adjuvant. The acceptable balance between efficacy and safety is obtained through the use of a specific adjuvant formulation. Montanide ${ }^{\mathrm{TM}}$ ISA adjuvants are based on a homogenous ready to use mix of purified mineral oils and refined oleic esters of anhydrous mannitol of vegetable origin. Emulsifying properties of specific surfactants can only be obtained through strict synthesis parameters, and have a direct impact on the vaccine safety and efficacy (Stone 1988). Furthermore, surfactants used in Montanide ${ }^{\mathrm{TM}}$ formulations are manufactured in dedicated equipment which avoids any cross contamination. The hydrophilic parts of these amphiphile molecules are made of mannitol sugar known to have better injectability than sorbitol-based surfactants. Adjuvant formulations of this quality do not induce adverse reactions observed when multipurpose industrial sorbitan oleate-based formulation (Tween/Span adjuvant formulation) is used. The Montanide ${ }^{\mathrm{TM}}$ ISA 206 VG renders a water-in-oil-in-water emulsion in a one step process, giving a very fluid vaccine when containing $50 \%$ of adjuvant. The Montanide ${ }^{\mathrm{TM}}$ ISA $70 \mathrm{VG}$ renders a water-in-oil emulsion containing $70 \%$ of adjuvant. In the later case, the antigenic media are entrapped in the oily phase. The different antigenic release profiles (Aucouturier et al. 2001) and the ratio of adjuvant to antigenic media can explain the perfect safety profile obtained with Montanide ${ }^{\mathrm{TM}}$ ISA 206 VG. Indeed, aqueous-based formulations are quickly eliminated from the injection site while water-in-oil 
emulsions ensure a long-lasting release of the antigens (Jansen et al. 2005).

The virulence of different challenge strains could be assessed through the monitoring of clinical scores in the unvaccinated control animals. The Tongaat C-3 strain demonstrated the highest virulence, followed by the C-2 and the A-1 strains. Serovar B did not induce any adverse reactions. The high clinical score recorded with serovar C-3 (1.01 and 1.65 after the first and the second challenge, respectively) is consistent with previous results (Bragg 2002a) and confirms the association of the C-3 serovars with most severe outbreaks in South Africa. The lack or poor virulence of South African serovar B has also been recorded previously (Bragg 2002a.)

Good levels of protection were, however, recorded for the C-3 serovar for all the vaccine formulations, at both challenges, which strengthen the value of vaccination for the control of IC in South Africa.

One of the main objectives of this experiment was to investigate the duration of protection provided by the different vaccines. In order to do this, the chickens were kept until they were older than 50 weeks. Vaccinated birds were then challenged with the same challenge strains as those used at approximately 30 weeks of age. The results of the second challenge with serovar C-3 in unvaccinated birds showed an increase of the mean disease score from 1.01 in the first challenge to 1.65 in the second challenge, indicating a possible worsening in bird susceptibility to the bacterium associated with increasing age. A similar increase in clinical signs as the birds aged was also recorded with the NADindependent C-3 strain, while the opposite was observed with the C-2 and the A-1 strains. Further work is required to confirm these observations. Differences of occurrence of IC in different age groups have been reported elsewhere with variations between different countries and production systems (Blackall 1999) who reported on a study of village chickens in Thailand where it was reported that IC was the most common cause of death in chickens less than 2 months old and in those over 6 months of age.

While the protection level with the ComA vaccine decreased from $81.1 \%$ to $64 \%$ from the first to the second challenge, the OBP CoryzaPlus vaccine generated an unchanged level of protection $(85.1 \%$ for the first challenge and $85.2 \%$ in the second challenge). The protection levels were found to increase to $90 \%$ when the Montanide ${ }^{\mathrm{TM}}$ ISA 70 VG and Montanide $^{\mathrm{TM}}$ ISA $206 \mathrm{VG}$ formulations were used.
The Montanide ${ }^{\mathrm{TM}}$ ISA 70 VG vaccine generated the best protection overall to all challenge strains, closely followed by the OVI vaccine. This can be attributed to the similarity in their formulation, water-in-oil and the inclusion of the NAD-independent C-3 strain. Montanide ${ }^{\mathrm{TM}}$ ISA $70 \mathrm{VG}$ also showed the best safety results. Larger field experiments are required to confirm the findings of the present study.

During the first round of challenge experiments, the clinical signs associated with IC in the unvaccinated control birds challenged with the Tongaat strain (C-3) were very severe. The levels of protection obtained when the different vaccinated groups of birds were challenged with serovar C-3 ranged from $64.4 \%$ (ISA 206) to $87.1 \%$ for the Montanide ${ }^{\mathrm{TM}}$ ISA 70 VG formulation.

The clinical signs obtained when unvaccinated birds were challenged with the serovar C-2 strain were less severe than those obtained when the unvaccinated birds were challenged with serovar C-3. These results confirm previous findings by Bragg (2002a). The levels of protection obtained by the different vaccines against the serovar $\mathrm{C}-2$ challenge ranged from $50.0 \%$ for the OBP vaccine to $100 \%$ for the ISA 70 formulation.

When unvaccinated birds were challenged with strain 0083 (serovar A-1), the clinical signs were less severe than those obtained in previous challenge experiments. The levels of protection obtained against challenge with serovar $A-1$ ranged from $52.7 \%$ for Montanide ${ }^{\mathrm{TM}}$ ISA $70 \mathrm{VG}$ and $69.1 \%$ obtained with the Montanide ${ }^{\mathrm{TM}}$ ISA 206 VG formulation.

When unvaccinated birds were challenged with serogroup $B$, no clinical signs were seen. Previous work has demonstrated that the South African serogroup B strains are of very low virulence (Bragg 2002b), but in those experiments, some clinical signs were recorded. The fact that no clinical signs were seen in the unvaccinated birds makes any comparison of the protection impossible.

The levels of virulence recorded with the different serovars correspond to the findings in South African strains of $A$. paragallinarum recorded by Bragg (2002a). The ability to protect birds through vaccination confirms the need for well-structured vaccination programmes.

The birds were also challenged with an NAD-independent strain of $A$. paragallinarum. In previous experiments, the virulence of both naturally occurring NAD-independent strains (Bragg 2002b) and ex- 
perimentally produced NAD-independent strains (Taole et al. 2002) were found to be of low virulence. It has also been demonstrated that the levels of protection obtained when vaccinated birds were challenged with the NAD-independent strains were very low (Bragg 2004). In the present study the prevalence of clinical signs noted in the unvaccinated birds was indeed very low: a mean disease score of only 0.15 was obtained in the unvaccinated birds challenged with the NAD-independent serovar C-3 strain as compared to a mean disease score of 1.01 obtained with the NAD-dependent serovar C-3 strain of $A$. paragallinarum.

The need for the inclusion of a NAD-independent strain in the vaccine was shown by the low protection level afforded by the commercial vaccine ComA, which lacks such a strain. The protection afforded by the commercial vaccine to a challenge with the NAD-independent strain improved however in late challenge, possibly as a result of an improved crossprotection over time with the other strains in the vaccine. These findings are in contrast to those of Jacobs et al. (2000) who demonstrated that the Nobilis coryza vaccine (Intervet International BV) provided protection against the NAD-independent strains in 9-week-old chickens vaccinated 2 weeks earlier, despite the fact that it does not include an NADindependent vaccine antigen. Bragg (2004), on the other hand, demonstrated that there was evidence of immune evasion by the NAD-independent strains when an experimental vaccine only containing NADdependent strains was used to vaccinate the birds. The difference between the finding of Jacobs et al. (2000) and Bragg (2004) could be attributed to the different challenge models used. Bragg et al. (2002b) demonstrated that the naturally occurring NAD-independent strains are of low virulence. Taole et al. (2002) showed that there is a substantial decrease in virulence when NAD-dependent strains of $A$. paragallinarum are experimentally converted to NADindependent strains. This low virulence level could account for the perceived efficacy of a vaccine against the NAD-independent strains as reported by Jacobs et al. (2000) Given the high prevalence of NAD-independent serovars in South Africa, their involvement in a number of outbreaks throughout the country, and previous observation of the limited ability of the NAD-dependent vaccine strain to protect birds against them, it is critical that vaccines in use in the country contain NAD-independent strains.

The two experimental vaccines, as well as the OBP CoryzaPlus vaccines contained an NAD-independent strain of $A$. paragallinarum, while the ComA vaccine did not. Protection levels of only $16.7 \%$ were recorded with ComA vaccine while it was between $46.7 \%$ (Montanide ${ }^{\mathrm{TM}}$ ISA $70 \mathrm{VG}$ ) and $73.3 \%$ (Montanide $^{\mathrm{TM}}$ ISA $206 \mathrm{VG}$ and OBP) for the vaccines containing an NAD-independent strain. These data clearly indicate the ability of a vaccine containing an NAD-independent strain to protect against these strains. In a previous study conducted in South Africa it was demonstrated that a commercial vaccine without an NAD-independent strain generated good protection against local NAD-independent C-3 strain (Jacobs et al. 2000). The fact that the chickens used in the experiment were vaccinated at 3 and 7 weeks of age and challenged 2 weeks later could explain the good level of protection recorded. In the present study the chickens were vaccinated and challenged much later (vaccination at 17 and 20 weeks, challenge at 33 or 55 weeks of age), in order to evaluate the level of protection at different stages of the productive life of layers. The results of the present experiment are certainly much closer to the layer production system and suggest the need for the use of a vaccine that includes NAD-independent strains in areas where NAD-independent variants are known to occur. The low virulence recorded for the NADindependent strains discussed above could also contribute to this discrepancy.

The results obtained in the present study confirm the variation in the virulence of different serovars occurring in South Africa, with serovar C-3 being the most virulent and serovar B having almost no virulence. The results indicate an age related increase in susceptibility to infection, as illustrated in the increased disease scores. The study highlights the importance of a suitable vaccine formulation that generates protection throughout the productive life of chickens and the need for incorporation of local dominant strains in the vaccine, including NADindependent strains.

\section{REFERENCES}

AUCOUTURIER J., DUPUIS L. \& GANNE V. 2001. Adjuvants designed for veterinary and human vaccines. Vaccine, 19: 2666-2672.

BLACKALL, P.J. 1999. Infectious coryza: overview of the disease and new diagnostic options. Clinical Microbiological Review, 12:627-32.

BLACKALL, P.J., EAVES, L.E. \& ROGERS D.G. 1990. Proposal of a new serovar and altered nomenclature for Haemophilus paragallinarum in the Kume hemagglutinin scheme. Journal of Clinical Microbiology, 28:1185-1187.

BLACKALL, P.J., CHRISTENSEN, H., BECKENHAM, T., BLACKALL, L.L. \& BISGAARD, M. 2005. Reclassification of Pasteurella gallinarum, Haemophilus paragallinarum, Pasteurella avium and Pasteurella volantium as Avibacterium gallinarum gen. nov. comb. nov., Avibacterium paragallinarum comb. 
nov., Avibacterium avium comb. nov. and Avibacterium volantium comb. nov. International Journal of Systematic and Evolutionary Microbiology, 55:353-362.

BRAGG, R.R. 2002a. Virulence of South African isolates of Haemophilus paragallinarum. Part 1: NAD-dependent field isolates. Onderstepoort Journal of Veterinary Research, 69: 163-169.

BRAGG, R.R. 2002b. Virulence of South African isolates of Haemophilus paragallinarum. Part 2: Naturally occurring NAD-independent field isolates. Onderstepoort Journal of Veterinary Research, 69:171-175.

BRAGG, R.R., COETZEE, L. \& VERSCHOOR, J.A. 1993. Plasmid encoded NAD independence in some South African isolates of Haemophilus paragallinarum. Onderstepoort Journal of Veterinary Research, 60:147-152.

BRAGG, R.R., COETZEE L. \& VERSCHOOR, J.A. 1996. Changes in the incidences of the different serovars of Haemophilus paragallinarum in South Africa; a possible explanation of vaccination failures. Onderstepoort Journal of Veterinary Research, 63:217-226.

BRAGG, R.R. 2004. Evidence of possible evasion of protective immunity by NAD-independent isolates of Haemophilus paragallinarum in poultry. Onderstepoort Journal of Veterinary Research, 71:53-58.

BUYS, S.B. 1982. Die bereiding van bakterieë teen Haemophilus paragallinarum besmetting, geskik vir Suid-Afrikaanse omstandighede. M.Med.Vet. thesis, University of Pretoria.

DROUAL, R., BICKFORD A.A., CHARLTON B.R., COOPER G.L. \& CHANNING, S.E. 1990. Infectious coryza in meat chickens in the San Joaquin Valley of California. Avian Diseases, 34:1009-1016.

DUPUIS, L., ASCARATEIL, S., AUCOUTURIER, J. \& GANNE, V. 2006. SEPPIC vaccine adjuvants for poultry. Annals of the New York Academy of Science, 1081:202-205.

HORNER, R.F., BISHOP, G.C., JARVIS, C.J. \& COETZEE, T.H.T. 1995. NAD (V-factor)-independent and typical Haemophilus paragallinarum infecting commercial chickens: a five year field study. Avian Pathology, 24:453-463.

JACOBS, A.A. \& VAN DER WERF, J. 2000. Efficacy of a commercially available coryza vaccine against challenge with re- cent South African NAD-independent isolates of Haemophilus paragallinarum in chickens. Journal of the South African Veterinary Association, 71:109-110.

JANSEN, T., HOFMANS, M.P.M., THEELEN, M.J.G., MANDERS, F. \& SCHIJNS V.E.J.C. 2006. Structure- and oil typebased efficacy of emulsion adjuvants. Vaccine, 24:54005405.

JANSEN, T., HOFMANS, M.P.M., THEELEN, M.J.G. \& SCHIJNS, V.E.J.C. 2005. Structure-activity relations of water-in-oil vaccine formulations and induced antigen-specific antibody responses Vaccine, 23:1053-1060.

KUME, K., SAWATA, A., NAKAI, T. \& MATSUMOTO, ? 1983. Serological classification of Haemophilus paragallinarum with a hemagglutinin system. Journal of Clinical Microbiology, 17: 958-964.

MIFLIN, J.K., HORNER, R.F., BLACKALL, P.J., CHEN, X., BISHOP, G.C., MORROW, C.J., YAMAGUCHI, T. \&. IRITANI, Y. 1995. Phenotypic and molecular characterization of V-factor (NAD)-independent Haemophilus paragallinarum. Avian Diseases, 39:304-308.

MOUAHID, M., BISGAARD, M., MORLEY, A.J., MUTTERS, R. \& MANNHEIM, W. 1992. Occurrence of V-factor (NAD) independent strains of Haemophilus paragallinarum. Veterinary Microbiology, 31:363-368.

PAGE, L.A. 1962. Haemophilus infections in chickens: I. Characteristics of 12 Haemophilus isolates recovered from diseased chickens. American Journal of Veterinary Research, 23:85-95.

TAOLE, M., ALBERTYN, J., VAN HEERDEN, E. \& BRAGG, R.R. 2002. Virulence of South African isolates of Haemophilus paragallinarum. Part 3: experimentally produced NAD-independent isolates. Onderstepoort Journal of Veterinary Research, 69:189-196.

TERZOLO, H.R., SANDOVAL, V.E. \& GONZALEZ PONDAL, F. 1997. Evaluation of inactivated infectious coryza vaccines in chickens challenged by serovar B strains of Haemophilus paragallinarum. Avian Pathology, 26:365-376.

STONE, H.D.1988. Optimization of hydrophile-lipophile balance for improved efficacy of Newcastle disease and avian influenza oil-emulsion vaccines. Avian Diseases, 32:68-73. 